\title{
Outcome of Endoscopic Discectomy in Patients with Lumbar Prolapsed Intervertebral Disc
}

\author{
FAIQ SHEIKH, ${ }^{1}$ FAHEEM AHMAD USMANI, ${ }^{1}$ HAMMAD MALIK ${ }^{1}$ \\ ANWAR CHAUDHRY, ${ }^{1}$ JAMAL NASIR ${ }^{2}$ \\ ${ }^{1}$ Department of Neurosurgery Unit-I, Punjab Institute of Neurosciences (PINS), Lahore General \\ Hospital (LGH), ${ }^{2}$ Children Hospital, Lahore - Pakistan \\ DOI: https://doi.org/10.36552/pjns.v23i3.364
}

\begin{abstract}
Objective: To determine the outcome of endoscopic discectomyin patients with lumbar prolapsed intervertebral disc in terms of back pain and leg pain using the visual analogue scale.

Material and Methods: Descriptive case series, was conducted at, PINS, LGH Lahore for 6 months. 15 patients were included through non probability consecutive sampling that fulfilled inclusion criteria. All patients' low back pain and leg pain was documented using visual analogue scale before and after 2 months of surgery. On the basis of VAS we calculated \% age improvement of low back pain and leg pain after endoscopic discectomy, while $\geq 5$ scale improvement was considered clinically significant.
\end{abstract}

Results: Patients mean age was 44.46 years. Among them, 9 (60\%) were males and 6(40\%) were females. On average, the basal metabolic index $\left(\mathrm{Kg} / \mathrm{m}^{2}\right)$ was 29.29 However, the BMI of females was 31.76 and male was $27.65 \mathrm{Kg} / \mathrm{m}^{2}$. On average, the duration of symptoms was 8.05 months. On average, the Straight Leg Raise was $24.7^{\circ}$ at the time of treatment. A decreased sensation was observed in $L_{5}$ of 3 (20\%) and in $S_{1}$ of $4(26.67 \%)$ participants. Whereas Absent sensation was observed in $L_{5}$ of $3(20 \%)$ and in $S_{1}$ of 5 (33.33\%). Mean preoperative back pain and as well as leg pain was 7.05 that improved to 0.41 and 0.864 weeks post operatively.

Conclusion: Endoscopic discectomy is equally effective in alleviating the symptoms without notable difference in surgical outcome.

Keywords: Prolapsed intervertebral disc, endoscopic discectomy, visual analogue scale.

\section{INTRODUCTION}

Lumbar prolapsed intervertebral disc is the displacement of intervertebral disc (nucleus pulposus or annulus fibrosis) beyond the edges of intervertebral disc. ${ }^{1}$ Back pain is experienced by $80 \%$ of the adult population at some point of their life time. ${ }^{2}$ The $5-$ $10 \%$ of low back pain is because of PIVD. It occurs predominantly in males. ${ }^{3}$ Back pain and leg pain due to PIVD in lumber region affects healthy adults in the 3rd to 5th decade of life. The majority of patients have herniation at level L4 - 5 and L5 - S1. ${ }^{4}$ The symptoms of PIVD vary depending upon the location where the herniation of the disc took place. The most common symptoms are alternating or continuous low back pain, leg pain, muscle weakness in legs, numbness in the leg or foot along with changes in bowel or bladder function. MRI is the investigation of choice to diagnose lumbar PIVD. Patients with lumbar PIVD should be given a trial of conservative management because $90 \%$ of the patients showed improvement in symptoms except for those with CES or with progressive or severe limb weakness. Various surgical approaches evolved over time to deal with PIVD; from standard laminectomy \& discectomy, hemi laminectomy, microscopic discectomy to endoscopic discectomy. Endoscopic discectomy, first described by Foley and colleagues in 1997, allowed surgeons to successfully operate on disc pathologies. Other advantages include small skin incision, less trauma to the muscles, less usage of analgesics, less hospital 
stay, early mobilization as well as early return to routine work. ${ }^{5}$ Being less invasive, shows comparable results in terms of back pain and leg pain has advantages in terms of better cosmesis and early mobilization which makes it more appropriate for treating PIVD. There are certain limitations of endoscopic discectomy as well; expensive, lack standardization, learning curve associated with performing this procedure due to the inconveniency in orientation with the scope, two - dimensional vision, less available space, difficulty in depth perception and failure to master hand eye coordination. ${ }^{6}$

\section{MATERIALS AND METHODS}

\section{Study Design}

Descriptive case study.

\section{Data Collection}

In this study, we aimed to see outcome in patients undergoing Endoscopic discectomy for lumbar PIVD in terms of post - operative Low back pain and radicular pain using the visual analogue scale. From February 2017 to July 2018, we recruited 15 patients fulfilling the inclusioncriteria and we performed the surgical procedure based on the standardized techniques outlined below. The patients were operated in elective operation theater of the Punjab institute of neurosciences. Demographic variables like name, age, gender, address and social status of the patients were recorded. Presenting complaints were noted and physical examination was done. X - Rays and MRI of the lumbar spine was done. Preoperatively VAS was documented of LBP and radiating leg pain. On the basis of VAS we calculated \% age improvement of low back pain and leg pain after endoscopic discectomy, while $\geq 5$ scale improvement was considered clinically significant. $^{7}$

\section{Inclusion Criteria}

In the study, both male and female patients of age 2060 years with uni-lateral PIVD, sequestrated PIVD, PIVD with semiology and the failure of conservative treatment of 6 weeks were asked to participate.

\section{Exclusion Criteria}

Patient not fit for general anesthesia, patients with redo surgery, multi-level PIVD, far lateral PIVD, diffuse disc bulge, post- traumatic PIVD, and patient with cauda equina syndrome were not included in the study.

\section{Operative Procedure}

After the induction of general anesthesia (GA), all patients were given 1 gram of Cefazolin preoperatively as antibiotic prophylaxis. The patient was put in prone position on Wilson frame with the spine flexed to open interlaminar space. Paint and drape were done. A local anesthetic agent was applied at the incision site. An incision was marked in anterior, posterior and lateral projection. The entry point was marked under fluoroscopic guidance using puncture needle at $1-1.5 \mathrm{~cm}$ lateral to midline.

An $18 \mathrm{~mm}$ skin incision was made. Sequential tube dilatations were performed to gently spread muscle fibers until appropriate size tubular retractors were placed.The working tube connected to the holder,the endoscope is inserted and connected to the camera. Orientation was done. The bony resistance of the lamina was felt. Inferior lamina was identified. Remnant muscle tissue removed with forceps and Kerrison punch.The upper two third of lower lamina and the lower one third of upper lamina were removed by high speed drill.

The ligamentum flavum was exposed.The ligament is incised with a scalpel. After incision it was partially removed with a punch. Dural margins and nerve roots were identified. Nerve root was retracted. The prolapseddisc was mobilized with hook and removed with grasping forceps. The wound was washed and closed in layers in reverse order.

\section{Data Analysis Procedure}

The collected data was analyzed by International Business Machine (IBM)) Statistical Package for Social Science (SPSS) version 21. Frequency and percentages were calculated for all qualitative variables like gender and improvement in LBP and leg pain. Grading of LBP and radicular pain was done using VAS preoperatively and on first post -operative day, then at 2 weeks and 4 weeks after surgery. The data was stratified by gender, age and control of symptoms. A $\mathrm{P}-$ Value of $<0.05$ was considered significant.

\section{RESULTS}

The patients' mean age was 44.46 years. Among them, $9(60 \%)$ were males and $6(40 \%)$ were females. On average, a basal metabolic index $\left(\mathrm{Kg} / \mathrm{m}^{2}\right)$ was 29.29 
However, a BMI of females was 31.76 and male was $27.65 \mathrm{Kg} / \mathrm{m}^{2}$. On average, the duration of symptoms was 8.05 Months. On average, theStraight Leg Raise was $24.7^{\circ}$ at the time of treatment. A decreased sensation was observed in $L_{5}$ of $3(20 \%)$ and in $S_{1}$ of 4 (26.67\%) participants. Whereas, the absent sensation was observed in $\mathrm{L}_{5}$ of $3(20 \%)$ and in $\mathrm{S}_{1}$ of 5 $(33.33 \%)$. No decrease or absent sensation was

Table 1: Distribution of patients based on preoperative clinical assessment.

\begin{tabular}{|l|l|l|}
\hline \multicolumn{2}{|l|}{ Preoperative clinical findings: } & \multicolumn{1}{c|}{$\begin{array}{c}\text { Frequency } \\
(\%)\end{array}$} \\
\hline $\begin{array}{l}\text { Motor Deficit } \\
\text { according to } \\
\text { myotome }\end{array}$ & $\mathrm{L}_{5}$ Myotome & $6(40 \%)$ \\
\cline { 2 - 3 } & $\mathrm{S}_{1}$ Myotome & $4(26.67 \%)$ \\
\hline \multirow{4}{*}{ Sensory Deficit } & Decrease sensation & $7(46.67 \%)$ \\
\cline { 2 - 3 } & Absent sensation & $8(53.33 \%)$ \\
\cline { 2 - 3 } & Absent ankle reflex & $6(40 \%)$ \\
\cline { 2 - 3 } & Saddle anesthesia & $2(13.33 \%)$ \\
\cline { 2 - 3 } & Absent Knee Jerk & $0(0 \%)$ \\
\cline { 2 - 3 } & Sphincter dysfunction & $0(0 \%)$ \\
\hline
\end{tabular}

observed in $\mathrm{L}_{4}$ Region.Mean pre-operative back pain and as well as leg pain was 7.05 that improved to 0.41 and 0.864 weeks post operatively.

\section{Preoperative Radiological Assessment}

The level of PIVD in 6(40\%) patients was L4-5 region and in $9(60 \%)$ was L5 \& S 1 region. Lumbar Disc height was decreased in 7 (46.67\%) patients on X-ray lumbosacral spine. Right sided disc prolapse was observed in 8 patients while left sided in 7. Location of PIVD was Central, Lateral, Far Lateral in 4/11/0 patients.

Table 2: Distribution of patients based on Intraoperative and postoperative Complications.

\begin{tabular}{|l|c|}
\hline Complications & Frequency (\%) \\
\hline Dural tear & $1(6.67 \%)$ \\
\hline Wound infection & $1(6.67 \%)$ \\
\hline Nerve root injury & $0(0 \%)$ \\
\hline CSF leak & $0(0 \%)$ \\
\hline Conversion to open & $0(0 \%)$ \\
\hline
\end{tabular}

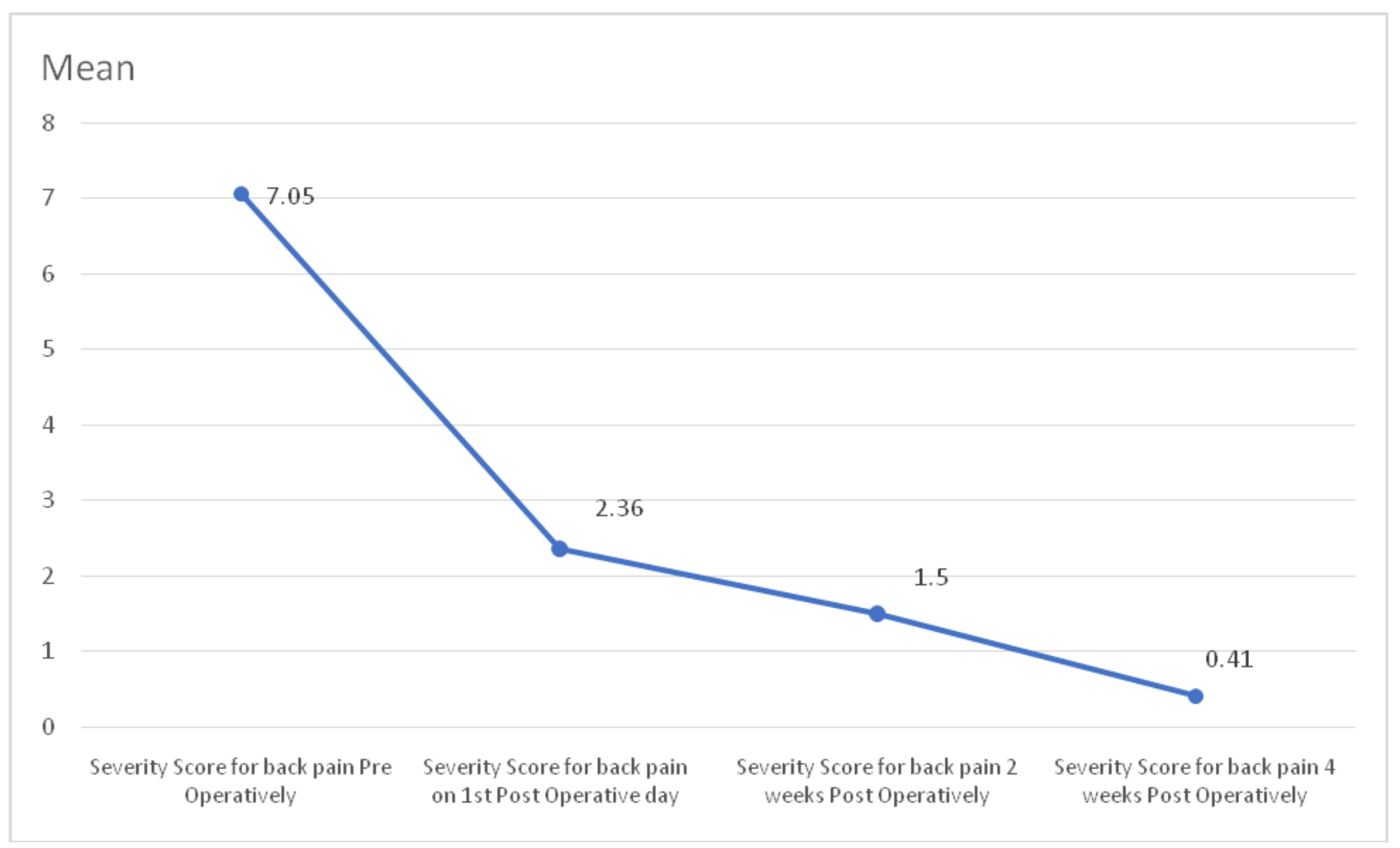

Graph 1: Graphical presentation of pre-op and post-op pain score for back pain. 


\section{Mean}

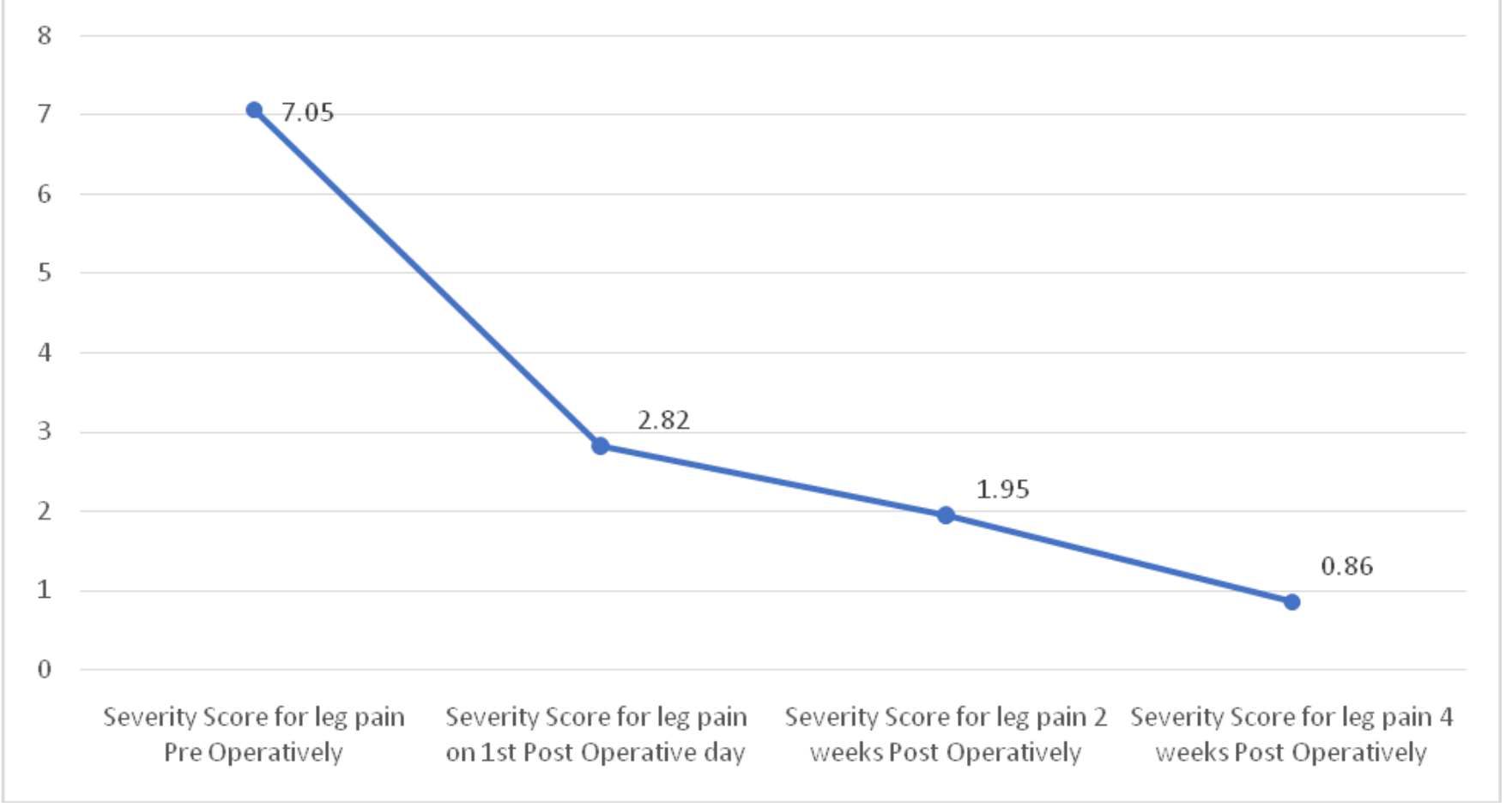

Graph 2: Graphical presentation of pre-op and post-op pain score for leg pain.

\section{DISCUSSION}

For decades, the standard laminectomy and discectomy had been the gold standard for lumbar PIVD and still practiced in Pakistan. Various studies showed acceptable outcome of this technique, but large skin incision massive bony work and dissection of bilateral para spinal muscles led to the development of less invasive procedure like hemi laminectomy and discectomy, microscopic discectomy and most recent is minimally invasive spine surgery/endoscopic discectomy. The ED's popularity is increasing because of smaller skin incision smaller scar, less postoperative pain, less hospital stays early mobilization and early return to work. The study included 15 patients fulfilling the inclusion criteria and having PIVD in the lumbar spine. ED was done using interlaminar approach with 2nd generation easy go system. Lumbar prolapsed intervertebral disc affects healthy adult population during 3rd to 5 th decade of life. It occurs predominantly in males. Powerful relation lies between BMI and Lumbar disc degeneration. Risk of lumbar disc degeneration increases population wise, having BMI $>25 \mathrm{~kg} / \mathrm{m} 2$. Mean BMI of patients was $29.29 \mathrm{~kg} / \mathrm{m}^{2}$. Females in our study had higher BMI as compared to male patients. Patients who were symptomatic for more than 6 months had poor outcome as compared to those having symptoms duration less than 6 months as mentioned in a review by Rhin et al in 2011. Before surgical treatment, 8.05 months was the mean duration of symptoms. Mean Straight leg raise (angle) was $24.7^{\circ}$. In order to diagnose lumbar PIVD, SLRT has been used as the chief tool of clinical examination. SLRT has effective correlation with MRI and symptomatic PIVD in patients with operative findings. Analgesics usage is higher in patients who have SLRT $<30$. SLRT has its strong positive correlation with the poor surgical outcome postoperatively. ${ }^{8}$ PIVD treatment is strictly based on the outcome of a clinical scoring system and less frequently on the neurological results. The motor and sensory symptoms might stay regardless appreciative clinical outcome in terms of pain measured by VAS. Improvement of back pain and leg pain was observed, on first post-operative day. Patients who didn't have any post-operative complication were discharged on the second postoperative day. The patients were then followed up in out-patient department 2 weeks and 4 weeks post- 
operatively. ED is equally beneficial in alleviating leg pain by decompressing the nerve root. The similar pattern of less back pain in early post-operative period was also perceived in different studies. ${ }^{9}$ For a surgeon to become proficient of ED, at least 10-20 cases are required. In ED technique according to a study there are higher chances of root injury, dural tear and recurrent disc as compared to standard and microscopic technique; with no wound infection after ED but equal incidence among standard and microscopic technique. 1 patient had Dural tear. Dural tear was sealed with fat and fibrin glue. One patient developed a wound infection that was treated with oral antibiotics. Less soft tissue injury in ED might be the reason of less wound infection after ED.Endoscopic technique has its certain limitations for surgeons because of poor perception of depth and the restricted movement of tubular retractors lead to iatrogenic injury to nerve root and dura and it requires learning curve to get oriented to instruments. A study establishes that in ED there is less tissue injury, the skin incision is also small and there is less use of analgesics in early post-operative period, which leads to less hospital stay and early mobilization. ${ }^{\mathbf{1 0}}$

\section{CONCLUSION}

Endoscopic discectomy is equally effective in alleviating the symptoms without notable difference in surgical outcome. Early mobilization is superior with ED but the long-term outcome is homogenous with rest of surgical techniques. The present-day principle of surgery is to deal pathology with minimally invasive technique. Neurosurgeons should master this technology, as this is the future of spine surgery.

\section{Additional Information}

Disclosures: Authors report no conflict of interest.

Human Subjects: Consent was obtained by all patients/ participants in this study.

\section{Conflicts of Interest:}

In compliance with the ICMJE uniform disclosure form, all authors declare the following:

Financial Relationships: All authors have declared that they have no financial relationships at present or within the previous three years with any organizations that might have an interest in the submitted work.

Other Relationships: All authors have declared that there are no other relationships or activities that could appear to have influenced the submitted work.

Address for Correspondence:

Dr. Jamal Nasir

Department of Neurosurgery Children Hospital,

Lahore Pakistan. Email: jamal.wahgra@gmail.com

\section{REFERENCES}

1. Joanne LJ, Kika K, JohnO. Herniated lumbar disc. BMJ. Clinical Evidence, 2011: 1118.

2. Kent PM, Jennifer L The epidemiology of low back pain in primary care.Chiropractic \& Osteopathy PMC. 2005; 13: 13.

3. Sangwan SS, Kundu ZS, Raj S, Kamboj P, Siwach RC. Lumbar disc excision through fenestration. IJO. 2006; 40: 86-89.

4. Battie MC and Videman T. Lumbar disc degeneration: epidemiology and genetics. J Bone Joint Surg Am. 2006; 88: 3-9.

5. Amit $\mathbf{J}$ and Manish M. Endoscopic lumbar discectomy Experience of first 100 cases. Indian J Orthop. 2010; 44 (2): 184-90.

6. Arvind GK, Anupreet. B, Abhilash. D. Microendoscopic lumbar discectomy:Technique and results of 188 cases. Indian J Orthop. 2014; 48 (1): 817.

7. Glaraza M, Gazzeri R, De L R P, Martinez L JF. Microdiscectomy with and without insertion of interspinous device for herniated disc at L5-S1 level. J Clinneurosci, 2014; 21 (11): 1934-39.

8. Jönsson B, Strömqvist B. Significance of a persistent positive straight leg raising test after lumbar disc surgery. J Neurosurg. 1999 Jul; 91 (1 Suppl.): 50-53.

9. Katayama Y, Matsuyama Y, Yoshihara H, Sakai Y, Nakamura H, Nakashima S,Ito Z, Ishiguro N Comparison of surgical outcomes between macro discectomy and micro discectomy for lumbar disc herniation: a prospective randomized study with surgery performed by the same spine surgeon. J Spinal Disord Tech. 2006; 19 (5): 344-47.

10. Mohinder K, and Ramesh B. Posterior Endoscopic Disectomy: Results in 300 patients.Indian Journal of Orthopedic, 2012; 46 (1): 81-85. 


\begin{tabular}{|c|c|c|c|}
\hline \multicolumn{4}{|c|}{ AUTHORSHIP AND CONTRIBUTION DECLARATION } \\
\hline Sr.\# & Author's Full Name & Intellectual/Contribution to Paper in Terms of: & \\
\hline 1. & $\begin{array}{l}\text { Faiq Sheikh } \\
\text { (Main/Principal Author). }\end{array}$ & $\begin{array}{l}\text { 1. Proposed topics and Basic Study Design, } \\
\text { methodology. }\end{array}$ & $\begin{array}{l}\text { Signature by the } \\
\text { author(s) }\end{array}$ \\
\hline 2. & $\begin{array}{l}\text { Fahem Ahmad Usmanii } \\
\text { (2nd Author) }\end{array}$ & 2. Data collection and calculations & \\
\hline 3. & $\begin{array}{l}\text { Adnan Khalid } \\
\text { (3rd Author) }\end{array}$ & 3. Analysis of data and interpretation of results etc. & $\begin{array}{l}\text { Hammad } \\
\text { (0) Paual }\end{array}$ \\
\hline 4. & $\begin{array}{l}\text { Anwar Chaudhry } \\
\text { (4th Author) }\end{array}$ & $\begin{array}{l}\text { 4. Literature review, manuscript writing and quality } \\
\text { insurer }\end{array}$ & Amwer \\
\hline 5. & $\begin{array}{l}\text { Jamal Nasir } \\
\text { (5th Author) }\end{array}$ & 5. Paper writing, referencing and Data Calculations & \\
\hline
\end{tabular}

Date of Submission: 12-07-2019

Date of Revision: 25-08-2019

Date of Online Publishing: 25-09-2019

Date of Print: 30-09-2019 